\title{
Rubén Darío, leitor de \\ Cruz e Sousa? \\ Uma hipótese \\ menosprezada de \\ Andrade Muricy
}

André Fiorussi

Doutorando no Programa de

Pós-Graduação em Língua

Espanhola e Literaturas

Espanhola e Hispano-Americana

da USP. Bolsista da FAPESP.

Contato: fiorussi@gmail.com 
CARACOL 4 / DOSSIÊ

Palavras-Chave
Rubén Darío; Cruz e Sousa;
poesia simbolista
KeYwords
Rubén Darío; Cruz e Sousa;
Symbolist Poetry

Symbolist Poetry
Resumo

$\mathrm{Na}$ introdução de seu Panorama do movimento simbolista brasileiro, Andrade Muricy levanta a possibilidade de Rubén Darío ter incorporado a seus poemas elementos da obra de Cruz e Sousa, que o haveria impressionado fortemente. A hipótese permanece pouco investigada. Embora sustentada por impressões e dados refutáveis, não convém descartá-la: a semelhança apontada é instigante e o inquérito que ocasiona pode esclarecer aspectos significativos da produção dos chamados simbolistas e de toda poesia escrita na América em torno do ano de 1900, sobretudo no que respeita aos modos de apropriação e imitação de técnicas compositivas entre poetas.

\section{ABSTRACT}

In the introduction to Panorama do movimento simbolista brasileiro, Andrade Muricy puts forward the hypothesis that Rubén Darío incorporated into his poems some elements of Cruz e Souza's works, which, according to Muricy, had caused a strong impression on Darío. This idea has yet been little investigated. Though supported by impressions and refutable data, it does not seem wise to discard Muricy's hypothesis: the similarity it points out is instigating, and a further discussion may shed remarkable light on the production of the so-called Symbolist poets and the entire poetical work produced in the Americas around the year 1900. This is specially true concerning the modes of appropriation and the imitation of compositional techniques among poets at that time. 
RUBÉN DARÍO, LEITOR DE CRUZ E SOUSA? UMA HIPÓTESE MENOSPREZADA DE ANDRADE MURICY ANDRÉ FIORUSSI

\section{INTRODUÇÃO}

$\mathrm{Na}$ introdução de seu Panorama do movimento simbolista brasileiro, José Cândido de Andrade Muricy levanta a possibilidade de o poeta nicaraguense Rubén Darío (I867-I9I6) ter incorporado a seus poemas elementos da obra de Cruz e Sousa (I86I-I898), poeta que o haveria impressionado fortemente:

Rubén Darío esteve no Rio, por uns meses, em I906, como secretário da Delegação da Nicarágua à Conferência Pan-Americana. Foi recebido por Elísio de Carvalho, que o iniciou nas nossas letras. A Cruz e Sousa já conhecia por intermédio de Más y Pí, Jaimes Freyre e Lugones. Aparecera poucos meses antes (I905), editado em Paris, Últimos Sonetos, do Poeta Negro, que lhe foi ofertado por Nestor Vítor. Rubén, personalíssimo e cioso de sua autonomia, impressionou-se, entretanto, fortemente. Resultou desse encontro um exercício poético, o inacabado soneto "Parsifal"; reflete flagrantemente a música inconfundível, o vocabulário e a temática dos sonetos de Cruz e Sousa. O poema introdutório do livro El Canto Errante, aparecido em I907, é da família de "Pandemonium", típico poema integrante de Faróis (I900). Do livro Poema del Otoño y Otros Poemas, de 1907, a poesia "La Cartuja" mostra, por sua vez, aquele cunho muito peculiar ao Simbolismo brasileiro, tão diferente do Modernismo hispano-americano, muito mais brilhante, maneiroso e muita vez eclético. (Andrade Muricy, I987, 102-3)

A hipótese permanece pouco investigada. Embora sustentada por impressões e dados refutáveis, não convém descartá-la: a semelhança apontada é instigante e o inquérito que ocasiona pode esclarecer aspectos significativos da produção dos chamados simbolistas e de toda poesia escrita na América em torno do ano de I900, sobretudo no que respeita aos modos de apropriação e imitação de técnicas compositivas entre poetas. 
Para um esclarecimento mais amplo da questão, haveria, é claro, que buscar um provável modelo comum europeu para ambos os poetas. O recorrido passaria certamente por Charles Baudelaire, Richard Wagner, J.-K. Huysmans e outros, em busca do vértice de um triângulo. É preciso levar em conta, todavia, que se trata de um triângulo não equilátero, cujos longos lados transatlânticos têm-nos sido muita vez mais familiares do que o lado menor. Aqui, procuraremos nos concentrar nessa relação direta entre dois poetas americanos, aproveitando-nos das pistas ainda inexploradas de que dispomos. Fique a possível compleição do triângulo como objeto futuro.

\section{O CASO}

Nenhum dentre os mais conhecidos estudos publicados sobre Rubén Darío até hoje investigou ou sequer mencionou a hipótese de Andrade Muricy; entre todos os textos críticos que pudemos consultar, apenas dedicou-lhe atenção o do norte-americano Fred P. Ellison (I968) ${ }^{\text {' }}$, um artigo sobre as relações entre Rubén Darío e o Brasil. Ellison argumenta contra a hipótese, que depois disso parece ter sido abandonada. O cotejo entre o parágrafo original de Andrade Muricy (I952) e o que transcrevemos acima, tomado da edição revisada e ampliada do Panorama ( $3^{\mathrm{a}}$ ed., I987), revela diferenças substanciais cujo sentido principal, faz-se supor, é atenuar a comparação em resposta à crítica de Ellison. Leia-se a seguir a transcrição do parágrafo tal qual foi publicado em I952:

Rubén Darío esteve no Rio, por uns meses, em I906, como secretário da Delegação da Nicarágua à Conferência Pan-Americana. Foi recebido por Elísio de Carvalho, que o

I Segundo o autor, partes desse artigo foram lidas em Salvador, em I959, no IV Colóquio Internacional de Estudos Luso-Brasileiros; e sua primeira publicação integral aconteceu na revista Hispania, mar. I964, vol. XLVII, n. I, pp. 24-25. Por uma ou outra via, supomos, o texto chegou ao conhecimento de Andrade Muricy. 
RUBÉN DARÍO, LEITOR DE CRUZ E SOUSA? UMA HIPÓTESE MENOSPREZADA DE ANDRADE MURICY ANDRÉ FIORUSSI

iniciou nas nossas letras. A Cruz e Sousa já conhecia por intermédio de Jaimes Freyre e Lugones. Aparecera poucos meses antes (1905), editado em Paris, Últimos Sonetos, do Poeta Negro. Rubén, personalíssimo e cioso de sua autonomia, impressionouse, entretanto, fortemente. Resultou desse encontro um curioso exercício poético, o inacabado soneto "Parsifal", que em vida o seu autor não colheu em livro. Reflete flagrantemente a música inconfundível, o vocabulário e a temática dos sonetos de Cruz e Sousa do livro citado. O poema introdutório do livro El Canto Errante, aparecido em I907, é ainda mais flagrantemente Cruz e Sousa, o dos dísticos de "Pandemonium". Do livro Poema del Otoño y Otros Poemas, de I907, na série "Otros poemas", a poesia "La Cartuja" mostra, por sua vez, aquele cunho irrecusável. E outros ainda. Nota-se que Cruz e Sousa o marcou para o resto da vida. (Andrade Muricy, I952, 70-I)

Observam-se, então, algumas alterações importantes do autor na edição revisada: a) inclusão do nome de Juan de Más y Pí ao lado de Jaimes Freyre e Lugones como prováveis intermediários; b) inclusão do dado de que Darío foi presenteado por Nestor Vítor com uma edição dos Últimos sonetos; c) no trecho a seguir, supressão das palavras que grifamos: "reflete flagrantemente a música inconfundível, o vocabulário e a temática dos sonetos de Cruz e Sousa do livro citado", em resposta à incompatibilidade de datas apontada por Ellison; d) no trecho a seguir, substituição das palavras que grifamos: "o poema introdutório do livro El Canto Errante, aparecido em I907, é ainda mais flagrantemente Cruz e Sousa, o dos dísticos de 'Pandemônium'” por "[...] em I907, é da família de 'Pandemonium', típico poema integrante de Faróis (I900)", atenuando e especificando a comparação; e) supressão integral da frase que encerrava o parágrafo: "Nota-se que Cruz e Sousa o marcou para o resto da vida”, substituída pela mais vaga e abrangente que se pode ler na transcrição do parágrafo publicado em 1987 . 
CARACOL 4 / DOSSIÊ

Tanto Andrade Muricy como Ellison pressupõem uma linha evolutivoprogressiva de conquistas e rupturas poéticas irreversíveis, na qual cada poeta é valorizado apenas enquanto proprietário exclusivo de seus recursos. Andrade Muricy pleiteia a presença de Cruz e Sousa em Darío como forma de exaltar a originalidade do poeta brasileiro, passando ao largo da possibilidade de ambos haverem chegado a soluções semelhantes com base em fontes comuns e em um conjunto compartilhado de técnicas que viabilizasse a incorporação à poesia de formas discursivas preexistentes. Ellison refuta a hipótese com vistas a proteger a originalidade de Darío - e, para tanto, se apoia também em dados nem sempre objetivos, além de deixar transparecer pouca familiaridade com a obra e a recepção de Cruz e Sousa. Assim, vale rever alguns pontos da discussão. Vamos por partes.

\section{Rubén Darío leu Cruz e Sousa?}

Embora "não haja", de fato, "provas de que Darío tenha lido as obras do bardo negro", como afirma Ellison, é muito plausível e mesmo segura a explicação de Andrade Muricy, segundo a qual o nicaraguense teria conhecido poemas de Cruz e Sousa por intermédio de Juan Más y Pí, Ricardo Jaimes Freyre e Leopoldo Lugones, ainda na década de I890. Cruz e Sousa teve poemas publicados em periódicos brasileiros ao longo de toda essa década (Teixeira, in Cruz e Sousa, I998a) e, em I893, lançou Broquéis, coleção de poemas que inclui alguns dos mais representativos de sua obra, como "Antífona" e "Ângelus". Como se sabe, era muito comum a propagação informal da fama dos chamados simbolistas, alimentando uma rede internacional e ensejando a rápida transmissão, inclusive transatlântica, de ideias poéticas. A título de exemplo, um dos poetas mais respeitados do simbolismo português, Camilo 
RUBÉN DARÍO, LEITOR DE CRUZ E SOUSA? UMA HIPÓTESE MENOSPREZADA DE ANDRADE MURICY ANDRÉ FIORUSSI

Pessanha, publicou esparsamente em revistas, o que não impediu a rápida disseminação de sua fama pelos cafés e salões lisboetas, através de manuscritos autógrafos que distribuía a amigos e ainda a declamações "de memória". Um de seus admiradores era Fernando Pessoa, que, em carta ao poeta (c.I9I5), deixou este precioso depoimento:

Há anos que os poemas de V. Ex. a são muito conhecidos e invariavelmente admirados por toda Lisboa. É para lamentar [...] que eles não estejam, pelo menos em parte, publicados. [...] Logo da primeira vez que nos vimos, fez-me V. Ex. a honra, e deu-me o prazer, de me recitar alguns poemas seus. [...] Obtive, depois, [...] cópias de alguns desses poemas. Hoje, sei-os de cor, [...] e eles são para mim fonte contínua de exaltação estética. (Pessoa, 2004, 4I7)

Quanto aos supostos intermediários hispano-americanos, merece maior atenção o poeta boliviano Jaimes Freyre. Tinha especial interesse pela literatura brasileira e lutou para divulgá-la na porção hispânica do continente. Chegaria a viver no Brasil na década de I920 como embaixador de seu país. Integrou o cenáculo modernista de Darío em Buenos Aires (a partir de i893) e manifestou em diversas ocasiões grande admiração por Cruz e Sousa - consta ter sido o primeiro a divulgá-lo amplamente fora do Brasil, ao proferir em I899, no Ateneo de Buenos Aires, uma conferência inteiramente dedicada a ele.

A conferência de Jaimes Freyre também só poderia versar sobre os Últimos sonetos, publicados seis anos depois? Claro que não. No texto lido, o autor deixa claro que conhece Broquéis, Missal e Evocações, e que não leu os livros posteriores, aos quais assim se refere: "Parece que hay aún tres volúmenes inéditos, Faroes, Últimos sonetos $y$ Prosas” (Jaimes Freyre, I899, 92). Certamente, então, o poeta boliviano leu Cruz e Sousa em algum momento entre I893 e 
CARACOL 4 / DOSSIÊ

I899, e, encontrando-se frequentemente nesse período com Darío, pode ter compartilhado seus livros com o amigo, sempre interessado na poesia de seus pares. Ellison lembra que Darío não pode ter comparecido à conferência, pois se mudara para a Europa; mas isso de modo algum implica em que não tenha tomado conhecimento do texto, seja parcialmente, via relatos, seja integralmente, pois El Mercurio de América publicou-o pouco mais tarde².

O jornalista e crítico catalão Más y Pí costumava encontrar-se com Darío em Buenos Aires no café "Los Inmortales", e mantinha contato com diversos intelectuais brasileiros, sobretudo com anarquistas gaúchos, como Guedes Coutinho, e fluminenses, como o poeta Elísio de Carvalho, também amigo de Darío (Broca, 2004, I72). Na primeira década do século XX, assinaria uma coluna sobre Letras brasileras na revista bonaerense Nosotros; com textos sobre Elísio de Carvalho, Machado de Assis, Alcides Maia e outros contemporâneos, consolidava seu papel de divulgador da literatura brasileira na parte hispanoparlante da América. Seu nome não constava do Panorama original: foi incluído na edição de I987, certamente com base em informações novas (de que não dispomos) e para fortalecer o argumento. Andrade Muricy afirma que:

o movimento simbolista brasileiro interessou-o apaixonadamente. Tratou logo de dar notícia dele para a Hispano-América. O seu prestígio no meio literário argentino, atestado por Álvaro Melián Lafinur, facilitou a aceitação passageira de Cruz e Sousa, que influiu diretamente sobre Leopoldo Lugones, o maior poeta argentino, 'como lo ha señalado Más y Pí’, escreveu Julio Noé. (Andrade Muricy, I987, IоI)

2 Cf. Jaimes Freyre, I899. Uma tradução ao português, feita por Antonio Carlos Santos, foi publicada na revista Travessia. Florianópolis: Editora da UFSC, n. 33, ago.-dez. 1996, pp. 60-69. 
RUBÉN DARÍO, LEITOR DE CRUZ E SOUSA? UMA HIPÓTESE MENOSPREZADA DE ANDRADE MURICY ANDRÉ FIORUSSI

Más y Pí exerceu um cargo de representação diplomática no Brasil e faleceu na costa brasileira, perto de Ilhabela, a caminho do porto de Santos, no naufrágio do transatlântico espanhol Príncipe de Astúrias, em igi6.

\section{O soneto "Parsifal", de Darío: o pivô da questão}

Sobre a semelhança entre "Parsifal" e a poesia de Cruz e Sousa, Ellison considera que "no es necesario un examen mayor a la luz de la fecha anterior del soneto de Darío" (Ellison, I968, 420). A refutação se apoia num frágil confronto de datas: presume que Darío só poderia ter lido Cruz e Sousa em I9o6, quando foi presenteado por Nestor Vítor no Rio de Janeiro com um exemplar parisiense de Últimos sonetos, publicado apenas um ano antes; mas "Parsifal" apareceu pela primeira vez em I899. Não nos parece, no entanto, que a comparação de Andrade Muricy se deva restringir aos Últimos sonetos - entre outros, os poemas de Broquéis podem, sem dúvida, ter chegado ao conhecimento de Darío antes da composição de "Parsifal", como dissemos. Por outro lado, Ellison toma por referência o ano de I899, quando se publicou pela primeira vez o soneto; mas dados levantados por Alfonso Méndez Plancarte permitem aventar a hipótese de que ele tenha sido redigido em I895, ou antes.

De fato, Darío nunca o incluiu em livro. Tanto Ellison como Andrade Muricy se referem a "Parsifal" como soneto inacabado porque, em livros posteriores que o coletaram, inexplicavelmente, sempre faltou o último terceto. É assim que aparece na coleção El modernismo y los poetas modernistas (Madrid, I929, p. I23) de Rufino Blanco-Fombona e em mais três publicações da primeira metade do século XX, incluindo as criticadas Obras Poéticas Completas do poeta nicaraguense organizadas por Alberto Ghiraldo, em Madri. Todavia, publicara-se integralmente na revista madrilena Blanco y Negro em 26 de maio 
CARACOL 4 / DOSSIÊ

de i9io e na bonaerense La Nota em i2 de agosto de I9I6; e, muito antes, na também bonaerense $\mathrm{El} \mathrm{Sol} \mathrm{(I} \mathrm{maio} \mathrm{I899).} \mathrm{Em} \mathrm{La} \mathrm{Nota,} \mathrm{consta} \mathrm{fotocópia} \mathrm{de} \mathrm{seu}$ manuscrito, datado assim: "Hospital San Roque. - Buenos Aires. - feb. 20. - dos p.m. - 1895.". Obtivemos as informações na edição de Méndez Plancarte; não pudemos consultar o manuscrito. Mas logramos encontrar outro documento relevante, desconhecido daquele editor: uma carta escrita por José Pardo a Darío em i8983, que menciona os sonetos ainda inéditos "Parsifal" e "Lohengrín".

Reproduzimos a seguir o pivô da questão - em versão completa, incluindo o segundo terceto, que Ellison e Andrade Muricy não chegaram a conhecer -, o soneto "Parsifal":

Violines de los ángeles divinos,

sones de las sagradas catedrales,

incensarios en que arden nuestros males,

sacrificio inmortal de hostias y vinos;

túnica de los más cándidos linos,

para cubrir a niños virginales;

cáliz de oro, mágicos cristales,

coros llenos de rezos y de trinos;

bandera del Cordero, pura y blanca,

tallo de amor de donde el lirio arranca,

rosa sacra y sin par del santo Graal:

3 Disponível em http://www.ucm.es/info/rdario, site do Archivo Rubén Darío, Universidad Complutense de Madrid, doc. n. 773. 
RUBÉN DARÍO, LEITOR DE CRUZ E SOUSA? UMA HIPÓTESE MENOSPREZADA DE ANDRADE MURICY ANDRÉ FIORUSSI

¡mirad que pasa el rubio caballero;

mirad que pasa, silencioso y fiero,

el loco luminoso: Parsifal! (Darío, I975, 963-4)

A coincidência de "vocabulário e temática" apontada por Andrade Muricy se pode notar, por exemplo, nestes versos do soneto "Incensos" (Broquéis) de Cruz e Sousa:

Dentre o chorar dos lânguidos violinos,

Por entre os sons dos órgãos soluçantes,

Sobem nas catedrais os neblinantes

Incensos vagos, que recordam hinos... (Cruz e Sousa, I998a, I97)

Que imagens e temas sejam bastante afins àqueles com que opera Cruz e Sousa não sustenta uma relação de imitação direta, pois provêm de um elenco comum a diversos poetas europeus das décadas finais do XIX. Por exemplo: ao final do Panorama, Andrade Muricy apõe um útil glossário dos vocábulos mais recorrentes na poesia dos simbolistas brasileiros; quase tudo o que aparece em "Parsifal" se pode encontrar nesse glossário. No poema de Darío, o vocabulário remete especificamente ao libreto da ópera homônima de Wagner, que reconta o mito medieval do cavaleiro Parsifal ou Percival, perseguidor do Santo Graal; além disso, tanto em Darío como em Cruz e Sousa, esse mesmo vocabulário adquire valor alegórico se cotejado com a simbologia de certas ordens religiosas, como a Rosa Cruz, de que teriam tomado participação o mesmo Wagner e

4 O soneto aparece com variações no volume bonaerense Poesías completas (Timón, I945, p. 813), cujo texto procede, segundo A. Méndez Plancarte, da imperfeita edição de Ghiraldo. V. 4: 'vino' por 'vinos'; v. 9: 'azul y blanca' por 'pura y blanca'; v. ıо: 'lino' por 'lirio'; v. II: 'Grial' por 'Graal'; além, é claro, da ausência do último terceto. 
CARACOL 4 / DOSSIÊ

também Victor Hugo, entre outros artistas admirados na segunda metade do século XIX.

Chama atenção, nos endecasilabos de "Parsifal", a sobreposição musical de construções exclusivamente nominais, que raramente aparece como traço fundamental em outros poemas de Darío. Já a poesia de Cruz e Sousa elege esse procedimento como principal, e, embora não o tenha inventado, deu-lhe tal e tão frequente uso que o transformou, com o constante apoio nas reiterações aliterativas, em marcante e particular traço estilístico. Parece-nos ser essa a sua "música inconfundível", que Andrade Muricy identifica em "Parsifal". O leitor de Cruz e Sousa saberá que isso não se refere apenas aos Últimos sonetos, mas também - e acima de tudo - aos poemas de Broquéis, de I893, inclusive a célebre "Antífona":

Ó Formas alvas, brancas, Formas claras

De luares, de neves, de neblinas!...

Ó Formas vagas, fluidas, cristalinas...

Incensos dos turíbulos das aras... [...] (Cruz e Sousa, I998a, I37)

Para reforçar a ilustração dos procedimentos poéticos de Cruz e Sousa que coincidem com os de "Parsifal", transcreve-se abaixo, a título de exemplo, a primeira estrofe de "Ângelus" (Broquéis):

Ah! lilases de Ângelus harmoniosos,

Neblinas vesperais, crepusculares,

Guslas gementes, bandolins saudosos,

Plangências magoadíssimas dos ares... $\quad$ (Cruz e Sousa, I998a, I90) 
RUBÉN DARÍO, LEITOR DE CRUZ E SOUSA? UMA HIPÓTESE MENOSPREZADA DE ANDRADE MURICY ANDRÉ FIORUSSI

Em Cruz e Sousa, a superposição de construções nominais com imagens vagas, diáfanas, vaporosas, líquidas etc. realiza o que Ivan Teixeira chamou de "arquitetura do vazio", isto é, se presta à composição de ambientes quase incorpóreos e imóveis, abeirando-se, no plano semântico-discursivo, de uma poesia "sem assunto" ou de assunto mínimo (Teixeira, 2004, 560). Viram-no alguns leitores coetâneos como originalíssima invenção, de efeito admirável; outros, como gerador de tediosa obscuridade. De modo geral, Darío prezará a variedade dos elementos compositivos e rejeitará a obscuridade em sua poesia, preferindo uma representação por alegorias transparentes e uma sintaxe mais simples e diversificada. Isso pode explicar, pelo menos em parte, a exclusão de "Parsifal" dos livros organizados em vida pelo autor. Outros poemas seus em que se acumulam sintagmas nominais têm diferenças substantivas em relação a "Parsifal", como "Heraldos" - referido pelo poeta como demonstração de sua teoria da melodia interior - e "Bouquet", especialmente a estrofe seguinte, uma pequena "sinfonia" dedicada à brancura de uma mulher:

Cirios, cirios blancos, blancos, blancos lirios,

cuellos de los cisnes, margarita en flor,

galas de la espuma, ceras de los cirios

y estrellas celestes tienen tu color. (Darío, I975, 564)

Nesses dodecasílabos, cada um dos sete primeiros hemistíquios comporta um membro do longo sujeito composto, e apenas o último hemistíquio traz o predicado. Trata-se de uma solução para que o acúmulo de frases nominais não se sobreponha à elegante fluidez discursiva perseguida por Darío.

O acúmulo de frases nominais em que prevalecem imagens vagas é um poderoso disparador da harmonia figurativa, uma vez que afasta a linearidade prosaica e oratória, ressaltando o corpo sonoro da linguagem. Embora não muito 
frequentes em Darío, as justaposições de frases nominais desempenham uma relevante função estilística em sua poesia enquanto evidenciam seu empenho em prover de variedade cada nível da composição poética. Reúnemse a seguir algumas ocorrências dessa construção em poemas de Darío com vistas a explicar o papel de cada uma em relação ao poema em que se encontra. Trata-se, como se verá, de poemas cujo traço comum é o discurso laudatório.

Os dodecasílabos de "Letanías de Nuestro Señor Don Quijote" (Cantos de Vida y Esperanza, 1905) vão acumulando títulos para a personagem cervantina:

Rey de los hidalgos, señor de los tristes,

que de fuerza alientas $y$ de ensueños vistes,

coronado de áureo yelmo de ilusión;

[...] iCaballero errante de los caballeros,

varón de varones, príncipe de fieros,

par entre los pares, maestro, salud! [...] (Darío, I975, 685)

Aqui, o recurso aparece para caracterizar o gênero - originalmente, "litania" é uma enumeração de nomes e símbolos da Virgem Maria. Mesmo assim, o poeta evita a monotonia inserindo verbos em orações subordinadas ("que de fuerzas alientas y de ensueños vives") ou amarrando os vocativos com uma saudação interjetiva (“isalud!”) que os justifica sintaticamente, como também nos dois versos iniciais da "Salutación del optimista" (Cantos de Vida y Esperanza): "Ínclitas razas ubérrimas, sangre de Hispania fecunda, / espíritus fraternos, luminosas almas, jsalve!” (Darío, I975, 63I). Dessa maneira, os vocativos e a expansão evocativa, permitem a composição de estrofes inteiras só com frases nominais, como esta, de "Nocturno" (Cantos de Vida y Esperanza): 
RUBÉN DARÍO, LEITOR DE CRUZ E SOUSA? UMA HIPÓTESE MENOSPREZADA DE ANDRADE MURICY ANDRÉ FIORUSSI

Esperanza olorosa a hierbas frescas, trino

del ruiseñor primaveral $y$ matinal,

azucena tronchada por un fatal destino,

rebusca de la dicha, persecución del mal... (Darío, I975, 657)

Mas a ausência de orações é compensada por uma rica variedade de recursos - enjambement, sinestesia, adjetivação exuberante etc. Darío sempre tem um antídoto contra a monotonia e a obscuridade. Outra solução adotada para que o acúmulo de frases nominais não se sobreponha à fluidez discursiva é transformar a enumeração num plurimembre sujeito composto ou numa sucessão de apostos. O sujeito composto resolve a "sinfonia" do já mencionado poema "Bouquet" (Prosas Profanas, i896). Já no poema de elogio ao frei Mamerto Esquiú (El Canto Errante, I907), com função apositiva, acumulam-se nominalmente atributos do homenageado:

Un báculo que era como un tallo de lirios,

una vida en cilicios de adorables martirios,

un blanco horror de Belcebú,

un salterio celeste de vírgenes $y$ santos,

un cáliz de virtudes $y$ una copa de cantos,

tal era fray Mamerto Esquiú. (Darío, I975, 7I8)

Dois poemas de Darío se distinguem por usar construções nominais como eixo composicional, "Heraldos" e "iAleluya!". Neste, da seção "Otros poemas" de Cantos de vida y esperanza, não há verbo algum: apenas substantivos, adjetivos, conectivos e um refrão interjetivo. A “aleluia” é um gênero litúrgico que, na Espanha, se converteu em gênero poético popular formado por versos octosílabos pareados com rimas consoantes - vê-se que Darío não cumpre 
CARACOL 4 / DOSSIÊ

à risca a prescrição formal do gênero, mas apenas a faz ressoar (com rimas internas e base octosilábica), imitando principalmente sua característica de jubilosa louvação. A aleluia foi bastante visitada pelos espanhóis da chamada "geração de 98", sobretudo Antonio Machado e seu irmão, Manuel, a quem o poema está dedicado.

Rosas rosadas y blancas, ramas verdes,

corolas frescas $y$ frescos

ramos, ¡Alegría!

Nidos en los tibios árboles,

huevos en los tibios nidos,

dulzura, ¡Alegría!

El beso de esa muchacha

rubia, y el de esa morena,

y el de esa negra, ¡Alegría!

Y el vientre de esa pequeña

de quince años, $y$ sus brazos

armoniosos, ¡Alegría!

Y el aliento de la selva virgen,

y el de las vírgenes hembras,

y las dulces rimas de la Aurora,

¡Alegría, Alegría, Alegría! (Darío, I975, 676)

O refrão "¡Alegría!" funciona como uma saudação que transforma as construções nominais em vocativos, como na litania para D. Quixote e na "Salutación del optimista". Nota-se que, mesmo num poema sem verbo, o poeta 
RUBÉN DARÍO, LEITOR DE CRUZ E SOUSA? UMA HIPÓTESE MENOSPREZADA DE ANDRADE MURICY ANDRÉ FIORUSSI

evita a enumeração puramente acumulativa e sugestiva, preferindo prover de sentido sintático e enunciativo os sintagmas nominais justapostos.

A assimilação de gêneros poéticos litúrgicos é frequente em Darío e nos poetas simbolistas. O glossário simbolista de Andrade Muricy registra, entre outros, os vocábulos antífona, de-profundis, evangeliário, kirie, litania e responso - todos provenientes da liturgia católica e abundantes em títulos de poemas e livros daqueles poetas em diversos países. No próprio título de Prosas profanas (I896), a palavra prosa alude a uma das antigas formas da poesia eclesiástica ${ }^{5}$ - uma espécie de versificação solta, sem medida, mas com rima ${ }^{6}$, frequentemente empregada pelo poeta conhecido como o primeiro da língua castelhana, Gonzalo de Berceo (II97-I264). Incompreendido o título, choveram diatribes sobre Darío, que, pacientemente, aguardou mais de dois anos até se revelar a erudita alusão. Afetando certo prazer vingativo, José Enrique Rodó, o "decifrador" do título, diz acreditar "que el autor [...] ha sonreído al pensamiento de que el público ingenuo se sorprenda de ver aplicado a tan exquisita poesía el humilde nombre de prosa" (Rodó, I899, 76). Note-se que a palavra prosa intitula, também nesse sentido, um poema de Mallarmé que tem sido considerado um dos mais herméticos produzidos pelos simbolistas: a "Prose pour Des Esseintes" (I885).

Há, portanto, que considerar as semelhanças notáveis entre o soneto "Parsifal" e certos poemas de Cruz e Sousa, esse verdadeiro achado de Andrade Muricy - mas sem tomá-las como provas de uma vaga "influência”. Bastante mais provável e adequado às práticas poéticas da época seria pensar que Darío,

5 Cf. Rodó (I899, 75-6): “[...] al cerrar el libro, algo hallo en la portada que me detiene para pedirme una opinión. Ha hecho hablar a la crítica el título de Prosas profanas, aplicado a un tomo de versos. [...] Creo que bastará con recordarles que el adjetivo [...] revelaba el propósito evidente de aludir a una de las antiguas formas de la poesía eclesiástica".

6 Cf. Henríquez Ureña, I998, I72. 
em "Parsifal", pode ter imitado Cruz e Sousa na eleição e no uso reiterado de técnicas poéticas que constituem aquela sua "música inconfundível", desde que se recordem pelo menos estes dois pontos: a) que, no vocabulário técnico poético, a categoria "música" designou, nas últimas décadas do século XIX, entre outras coisas, algo como "estilo particular", podendo assim descrever-se em termos mais objetivos do que supõe uma leitura ingênua da associação discursiva entre "música" e "inspiração (da musa)"; b) que a imitação e a apropriação de técnicas e traços estilísticos constituíam prática recorrente e mesmo fundamental entre poetas, integrando um propósito de versatilidade e politecnia cujo modelo era ainda Victor Hugo. Quando qualifica Rubén Darío de "personalíssimo e cioso de sua autonomia", Andrade Muricy (I987, I02) se esquece providencialmente de objetar que se encontram na obra do poeta nicaraguense versos prodigamente variados tanto em medida como nos diversos elementos compositivos com que operam.

\section{OUTRAs PISTAS}

As outras duas comparações estabelecidas por Andrade Muricy não oferecem muita resistência à investigação. Quanto a "El canto errante", poema de abertura do livro homônimo que seria "da família de 'Pandemonium', típico poema integrante de Faróis (I900)" (Andrade Muricy, I987, I03), parece-nos acertada a dura refutação de Ellison:

[...] aun el más indiferente observador puede ver que a pesar de estar ritmado en coplas, una forma muy socorrida por los hispanoamericanos, no le debe nada a el "Pandemôniums" de Cruz e Souza, donde, en dísticos de un metro totalmente diferente, el autor de Broquéis contempla una melancólica visión del infierno (Ellison, I968, 42I). 
RUBÉN DARÍO, LEITOR DE CRUZ E SOUSA? UMA HIPÓTESE MENOSPREZADA DE ANDRADE MURICY ANDRÉ FIORUSSI

E a manifestação, vagamente apontada, de um cunho peculiarmente brasileiro em "La cartuja" de Darío não nos parece fazer sentido, sendo este um poema cujos temas, imagens e assuntos foram visitados por inúmeros poetas do fim do XIX. Na primeira edição do Panorama, Andrade Muricy apontava diretamente o poema de Cruz e Sousa que teria dado origem a "La cartuja"; após a revisão, substituiu essa indicação precisa por uma comparação bastante mais vaga.

\section{CONCLUSÃo}

Em rigor, portanto, é preciso aceitar ainda hoje a validade do julgamento de Ellison: "En vista de la evidencia uno está obligado a concluir que la afirmación de la deuda de Darío a João Cruz e Sousa sigue sin probarse" (Ellison, I968, 42I). Por outro lado, fica aberta a grande probabilidade de que Darío tenha conhecido a obra de Cruz e Sousa, mesmo sem nunca a ter mencionado registre-se que o nicaraguense tampouco "assumiu dívida" com poetas como José Asunción Silva, de cujo "Nocturno" emprestou muito provavelmente a técnica de compor versos polimétricos com repetição de uma única célula rítmica, empregada em "Marcha triunfal" e outros poemas.

\section{REFERÊNCIAS BIBLIOGRÁFICAS}

Andrade Muricy, José Cândido de. Panorama do movimento simbolista brasileiro. I ed. Rio de Janeiro: Departamento de Imprensa Nacional, I952. / $3^{\mathrm{a}}$ ed. revisada e ampliada. São Paulo: Perspectiva, I987.

Broca, Brito. A vida literária no Brasil: 1900. Rio de Janeiro: José Olympio, 2004. Cruz e Sousa, João da. Missal e Broquéis. I. Teixeira (org. e prefácio). São Paulo: Martins Fontes, I998. 
CARACOL 4 / DOSSIÊ

Cruz e Sousa, João da. Faróis. I. Teixeira (apresentação). Florianópolis: FCC; São Paulo: Ateliê, I998.

Darío, Rubén. Poesías completas. Ed. A. Méndez Plancarte. Madrid: Aguilar, I975.

Ellison, Fred P. “Rubén Darío y Brasil”. In: Mejía Sánchez, E. (org.), Estudios sobre Rubén Darío. México: FCE, I968, 4I9-2I.

Henríquez Ureña, Pedro. "En busca del verso puro" (I926). In: Ensayos. Ed. crítica de J.L. Abellán y A.M. Barrenechea. México: FCE, I998.

Jaimes Freyre, Ricardo. “Literatura brasilera (Cruz e Sousa)”. In: El Mercurio de América, Buenos Aires, tomo III, año II, septiembre y octubre I899, 8I-96.

Pessoa, Fernando. Obras em prosa. Ed. C. Berardinelli. Rio de Janeiro: Nova Aguilar, 2004.

Rodó, José Enrique. Rubén Darío: su personalidad literaria, su última obra. Montevideo: Imp. Dornaleche y Reyes, I899.

Teixeira, Ivan. "O verso harmônico em Mário de Andrade e Cruz e Sousa". In: Junqueira, Ivan (coord.). Escolas literárias no Brasil. Tomo II. Rio de Janeiro: Academia Brasileira de Letras, 2004, 555-576. 
